\title{
Surface processing using water cluster ion beams
}

\author{
$\operatorname{AUTHOR}(\mathrm{S}):$ \\ Takaoka, Gikan H.; Ryuto, Hiromichi; Takeuchi, \\ Mitsuaki; Ichihashi, Gaku
}

\section{CITATION:}

Takaoka, Gikan H. ... [et al]. Surface processing using water cluster ion beams. Nuclear Instruments and Methods in Physics Research Section B: Beam Interactions with Materials and Atoms 2013, 307: 33-36

ISSUE DATE:

2013-07-15

URL:

http://hdl.handle.net/2433/179394

\section{RIGHT:}

C 2013 Elsevier B.V.; この論文は出版社版でありません。引用の際には 出版社版をご確認ご利用ください。; This is not the published version. Please cite only the published version. 


\title{
Surface Processing Using Water Cluster Ion Beams
}

\author{
Gikan H. Takaoka*, Hiromichi Ryuto, Mitsuaki Takeuchi and Gaku Ichihashi \\ Photonics and Electronics Science and Engineering Center, Kyoto University \\ Katsura, Nishikyo-ku, Kyoto 615-8510, Japan
}

\begin{abstract}
Vaporized water clusters were produced by an adiabatic expansion phenomenon, and various substrates such as $\mathrm{Si}(100), \mathrm{SiO}_{2}$, polymethyl methacrylate (PMMA), polyethylene terephthalate (PET), and polycarbonate (PC) were irradiated by water cluster ion beams. The sputtered depth increased with increasing acceleration voltage, and the sputtering rate was much larger than that obtained using Ar monomer ion irradiation. The sputtering yield for PMMA was approximately 200 molecules per ion, at an acceleration voltage of $9 \mathrm{kV}$. X-ray photoelectron spectroscopy (XPS) measurements showed that high-rate sputtering for the PMMA surface can be ascribed to the surface erosion by the water cluster ion irradiation. Furthermore, the micropatterning was demonstrated on the PMMA substrate. Thus, the surface irradiation by water cluster ion beams exhibited a chemical reaction based on $\mathrm{OH}$ radicals, as well as excited hydrogen atoms, which resulted in a high sputtering rate and low irradiation damage of the substrate surfaces.
\end{abstract}

Keywords: Water cluster, Ion beam processing, Surface reaction, Sputtering 


\section{Introduction}

It is thought that liquid water exhibits different properties depending on the network of hydrogen bonds in water molecules. In recent years, experimental and theoretical studies have been carried out to investigate the microscopic structure of liquid water. It has been discussed in terms of clusters of water molecules [1-3], although it is not possible to analyze the cluster size. Also, liquid water has been applied as a surface treatment for solid surfaces as a wet process. It is used for cleaning the surfaces but etching has not been achieved even at elevated temperatures. The development of new phases of water such as functional water and supercritical state water has received special interest from the fundamental and applicable viewpoints $[4,5]$.

The ion beam process is one of the basic technologies in nanostructure fabrication [6]. It represents several features in material processing, one of which is that it can transfer charge, energy, and mass such that they can be employed for material surface treatment. Another feature is that various species such as atomic, molecular, and cluster ions are available [7]. In particular, polyatomic molecular ions such as water and alcohol ions contain a variety of radicals such as hydroxyl and alkyl radicals, and these radicals have an important role in surface modification and chemical erosion of material surfaces.

Furthermore, the physical and chemical properties of clusters are unique and different from those in the bulk state $[8,9]$. In addition to the unique properties of clusters, the impact of cluster ions on solid surfaces offers specific features that cannot be obtained by conventional monomer ion beams [10,11]. For example, the incident energy of a molecule in a cluster is the accelerating energy divided by the cluster size, and this incident energy is very low. Therefore, the irradiation damage induced by polyatomic cluster ions such as water and alcohol cluster ions is less than that by $\mathrm{Ar}$ monomer ion beams $[12,13]$. Because thousands of molecules impact the target at 
almost the same time, the many-body interactions between clusters and target atoms are induced by the dense energy deposition. The high-energy density deposition and the collective motions of the clusters during impact play important roles in the surface process. This process makes it possible to achieve an extremely high temperature of the impact area by cluster ion irradiation [14]. Therefore, the chemical reaction on the surface can be enhanced by accelerating polyatomic cluster ion beams.

In this paper, we focus on water clusters as the polyatomic cluster, and the interaction of water cluster ions with solid surfaces is investigated. The chemical reactivity of water cluster ions is discussed based on the role of the hydroxyl radicals and hydrogen atoms produced. In addition, physical and chemical sputtering by water cluster ion irradiation is discussed, and micropatterning is demonstrated on polymethyl methacrylate (PMMA) surfaces with water cluster ion beams.

\section{Experimental}

A polyatomic cluster ion beam system was previously developed, and the details of the system are described elsewhere [15]. Liquid water and alcohol were placed in a metal box, and they served as the source for the production of clusters. The liquid materials were heated to $150^{\circ} \mathrm{C}$ by a wire heater attached around the source, and the vapors of the liquids were ejected through a nozzle into a vacuum region. The converging-diverging supersonic nozzle was made of glass, and had a throat diameter of $0.1 \mathrm{~mm}$. The vapor pressure was monitored by a pressure gauge connected to the cluster source. When the vapor pressure is high, 0.1 MPa for water, for example, a vaporized cluster is produced by an adiabatic expansion phenomenon without the addition of helium gas. The cluster size distribution was measured by the time-of-flight (TOF) method. In the TOF measurement, it was assumed that the cluster ion had a single charge. The size distribution measured was broad and it had a peak. The peak size could be considered to correspond to the average size, which increased with 
increasing vapor pressure. The cluster size was approximately 2500 molecules for water clusters at a vapor pressure of $0.3 \mathrm{MPa}$.

The produced water clusters passed through a skimmer and a collimator, and then entered an ionizer. Inside the ionizer, the neutral clusters were ionized by electron bombardment. The electron voltage for ionization $\left(V_{e}\right)$ was adjusted to be between $0 \mathrm{~V}$ and $300 \mathrm{~V}$, and the electron current for ionization $\left(I_{e}\right)$ was adjusted to be between $0 \mathrm{~mA}$ and $250 \mathrm{~mA}$. The cluster ions were accelerated by applying an extraction voltage to the extraction electrode. The extraction voltage was adjusted to be between $0 \mathrm{kV}$ and $2 \mathrm{kV}$. The extracted cluster ions were separated according to size using a retardation potential method, and the clusters used were those larger than 100 molecules per cluster. These large-cluster ion beams were accelerated toward a substrate that was placed on a substrate holder. The acceleration voltage $\left(V_{a}\right)$ was adjusted to be between $0 \mathrm{kV}$ and $10 \mathrm{kV}$. The beam size at the substrate holder was adjusted by an electrostatic lens to be approximately $2 \mathrm{~cm}$ in diameter. The uniformity of the ion beams was typically $10 \%$. The ion current was measured by a Faraday cup and the fluence was estimated by the ion current. The substrates used were silicon $(\mathrm{Si}), \mathrm{SiO}_{2}$, polymethyl methacrylate (PMMA), polyethylene terephthalate (PET) and polycarbonate (PC). The substrate temperature was at room temperature. A background pressure of $8 \times 10^{-5} \mathrm{~Pa}$ was maintained around the substrate using a diffusion pump.

\section{Results and Discussion}

\subsection{Sputtering rate and chemical reactions}

The sputtered depths of $\mathrm{Si}(100)$ and $\mathrm{SiO}_{2}$ surfaces by water cluster ion irradiation were measured using the DEKTAK-3173933 step profiler by Veeco Instruments. Figure 1 shows the dependence of the sputtered depth on the acceleration voltage for water cluster ions. The experimental error about the sputtered depth was typically $6 \%$. The electron voltage for ionization $\left(V_{e}\right)$ was $200 \mathrm{~V}$ and the electron current for ionization $\left(I_{e}\right)$ 
was $200 \mathrm{~mA}$. The vapor pressure was $0.3 \mathrm{MPa}$ and only clusters larger than 100 molecules per cluster were used. The fluence was maintained at $1.0 \times 10^{16}$ ions $/ \mathrm{cm}^{2}$. As shown in Fig. 1, the sputtered depths of $\mathrm{Si}$ and $\mathrm{SiO}_{2}$ were very similar and the sputtered depths increased with increasing acceleration voltage. Taking into account the sputtered depth and the ion dose, the sputtering yield was calculated by first estimating the density of $\mathrm{Si}$ and $\mathrm{SiO}_{2}$ to be $2.42 \mathrm{~g} / \mathrm{cm}^{3}$ and $2.63 \mathrm{~g} / \mathrm{cm}^{3}$, respectively. The sputtering yield at an acceleration voltage of $9 \mathrm{kV}$ is 19.2 atoms per ion for $\mathrm{Si}$ and 13.2 molecules per ion for $\mathrm{SiO}_{2}$, which is approximately ten times larger than the sputtering yield obtained using Ar monomer ion irradiation. Furthermore, for the $\mathrm{SiO}_{2}$ surface, the thermal evaporation of $\mathrm{SiO}_{2}$ molecules in the molecular state could be enhanced at an acceleration voltage of $9 \mathrm{kV}$ because the impact area of water cluster ions increases at high temperatures.

After bombardment of the Si surface by the water cluster ions, surface oxidation occurs. The resulting $\mathrm{OH}$ radicals have important roles in the oxidation process due to the implantation and diffusion processes. Because the silicon oxide layer has a higher surface binding energy than the Si surface, there are fewer chemical effects due to sputtering of the oxide layer. Instead, physical sputtering occurs due to the bombardment of cluster ions with energy higher than a few tens of electron volts per molecule, although the number of cluster ions involved in physical sputtering is small. The incident energy of the cluster ions, which is larger than the chemical sputtering energy, is transferred to the oxide layer by the physical sputtering process. As a result, the sputtered depth of $\mathrm{Si}$ surfaces is similar to that of $\mathrm{SiO}_{2}$ surfaces.

Figure 2 shows the sputtered depths of PMMA, PET, and PC surfaces irradiated at different acceleration voltages by water cluster ion beams. The fluence was $1.0 \times 10^{16}$ ions $/ \mathrm{cm}^{2}$. As shown in Fig. 2, the sputtered depths increased with increasing acceleration voltage. In particular, PMMA surfaces were sputtered more than PET and PC surfaces. By estimating the density of PMMA to be $1.19 \mathrm{~g} / \mathrm{cm}^{3}$, the sputtering yield 
was 206 molecules per ion at an acceleration voltage of $9 \mathrm{kV}$. The high sputtering rate of PMMA substrates occurs because of the ejection of sputtered particles as a monomer unit due to the cluster ion irradiation. This is different from the monomer ion irradiation case, in which all the bonds in the polymer substrate are easily broken by the irradiation of high-energy monomer ion beams. Moreover, for PMMA substrates irradiated by water cluster ions, it is thought that the PMMA surface changes to a polymethacrylic acid surface, which has a melting point that is lower than room temperature and is dissolvable in water. The impact of water cluster ions on the changed surface enhances the ejection of methacrylic acid molecules in the monomer state from the surface. Therefore, the high sputtering rate of PMMA surfaces is achieved by both the chemical erosion of the surface and the momentum transfer of the incident energy of the water cluster ion irradiation.

The surface state of the PMMA substrates irradiated by the water cluster ion beams was investigated using X-ray photoelectron spectroscopy (XPS) measurement. Figure 3 shows the C1s peaks for the PMMA surfaces, both unirradiated and irradiated at acceleration voltages of $3 \mathrm{kV}$ and $9 \mathrm{kV}$. The fluence was $1.0 \times 10^{16}$ ions $/ \mathrm{cm}^{2}$. PMMA is a polymer with a molecular structure of $\mathrm{CH}_{2}=\mathrm{C}\left(\mathrm{CH}_{3}\right) \mathrm{COOCH}_{3}$. When the radical $\left(\mathrm{COOCH}_{3}\right)$ changes to a carboxyl radical $(\mathrm{COOH})$, PMMA changes to polymethacrylic acid. As shown in the figure, there are four peaks corresponding to the unirradiated PMMA surface, which correspond to the binding energies of carbon atoms indicated in numbers (I) to (IV) [16]. These peaks correspond to (I) $\mathrm{C}-\mathrm{C}$ or $\mathrm{C}-\mathrm{H}$, (II) - C<, (III) $-\mathrm{CH}_{3}$, and (IV) $\mathrm{O}^{-} \mathrm{C}=\mathrm{O}$, respectively. The atomic concentration of carbons corresponding to each peak is $36.1 \%$ for (I), $24.2 \%$ for (II), $21.1 \%$ for (III), and $18.6 \%$ for (IV).

For the irradiated surfaces, additional peaks indicated by numbers (V) and (VI), which correspond to $-\mathrm{C}=\mathrm{O}$ and $-\mathrm{COOH}$, respectively, appear for the irradiated surface. These peaks are related to the formation of a carboxyl radical (COOH). For PMMA substrates irradiated by water cluster ions, the chemical erosion of the PMMA 
substrate surfaces occurs either through the exchange of the $\mathrm{CH}_{3}$ radical in $\mathrm{COOCH}_{3}$ with an $\mathrm{H}$ atom of the water cluster or through the exchange of an $\mathrm{OCH}_{3}$ radical with an $\mathrm{OH}$ radical. Furthermore, these peaks increase with increasing acceleration voltage, which results in enhancement of the formation of carboxyl radicals. In contrast, the peak corresponding to (IV) decreases. This indicates that the radical $\left(\mathrm{COOCH}_{3}\right)$ decreases. Therefore, the PMMA surface is modified to a polymethacrylic acid surface, which is dissolvable in water. This modification has an important role in the high sputtering rate of PMMA surfaces irradiated by water cluster ion beams.

\subsection{Micropatterning}

PMMA has attracted interest as an organic glass, and it has been used in various kinds of chemical devices such as microreactors. To demonstrate an engineering application of the high sputtering rate and low irradiation damage as a result of using water cluster ion beams, a patterning process was performed on the PMMA surface. The acceleration voltage was $9 \mathrm{kV}$ and the fluence was $3.0 \times 10^{16}$ ions $/ \mathrm{cm}^{2}$. The patterns were measured using the laser microscope by Keyence Corporation. As shown in Fig. 4, a micropattern of the letters "KYOTO" was etched onto the PMMA substrate and the sputtered depth of the substrate was approximately $10 \mu \mathrm{m}$. The high sputtering rate of the PMMA substrate is due to the chemical sputtering by water cluster ion irradiation. However, the width of a letter prepared was larger than the original one on the metal mask, i.e., $>50 \mu \mathrm{m}$. This increase of the width could be ascribed to the surface diffusion of water molecules on the PMMA surface under the mask by the water cluster ion irradiation. If the contact of the mask on the substrate could be improved, a sharp-edged pattern would be achieved.

\section{Conclusion}


Water clusters were produced by using the adiabatic expansion phenomenon. The intensity of the clusters increased with increasing vapor pressure, and the peak size was approximately 2500 molecules per cluster. Various substrates such as $\mathrm{Si}(100), \mathrm{SiO}_{2}$, PMMA, PET, and PC were irradiated at room temperature by water cluster ion beams. For $\mathrm{Si}(100)$ and $\mathrm{SiO}_{2}$ surfaces irradiated at different acceleration voltages, the ratio of the sputtered depth for $\mathrm{Si}(100)$ and $\mathrm{SiO}_{2}$ surfaces was almost unity at an acceleration voltage of $6 \mathrm{kV}$. The physical sputtering of $\mathrm{Si}(100)$ surfaces was found to occur through surface oxidation. Furthermore, for PMMA, PET, and PC surfaces, a high sputtering rate was achieved by adjusting the acceleration voltage. This occurred because of the ejection of sputtered particles as a monomer unit of the polymer due to the cluster ion irradiation. This was different from the monomer ion irradiation case, in which all the bonds in the polymer substrate were considered to be easily broken by the irradiation of high-energy monomer ion beams. XPS measurements showed that the extremely high sputtering rate of PMMA surfaces was achieved by both the chemical erosion of the surface and the momentum transfer of the incident energy of the water cluster ion irradiation. To demonstrate an engineering application of the high sputtering rate and low irradiation damage by water cluster ion beams, micropatterning was performed on PMMA substrates.

Acknowledgements

This work was partially supported by Nanotechnology Support Project of the Ministry of Education, Culture, Sports, Science and Technology, Japan. 
References

[1] J.P. Devlin, J. Sadlej, V. Buch, J. Phys. Chem. A105 (2001) 974.

[2] S.K. Ghosh, P.K. Bharadwaj, Eur. J. Inorg. Chem. (2005) 4886.

[3] I.B. Muller, L.S. Cederbaum, J. Chem. Phys. 125 (2006) 204305.

[4] O. Mishima, H.E. Stanley, Nature, 392 (1998) 164.

[5] F. Cansell, C. Aymonier, A. Loppinet-Serani, Solid State \& Mater. Sci. 7 (2003) 331.

[6] Mater. Res. Soc. Proc. 2007, Vol.1020, Chap. Session: Ion Beam Nanofab: Tools, Techniques, and Applications, p.3

[7] Proc. 17th Int. Conf. on Ion Implant. Technol. IIT2008, (AIP Conf. Proc., 2008, Vol.1066), Chap. Session: Molecular and Cluster Ion Beams. p.387.

[8] Ph. Buffat, J-P. Borel, Phys. Rev. A13 (1976) 2287.

[9] M.D. Morse, Chem. Rev. 86 (1986) 1049.

[10] R.S. Averback, M. Ghaly, H. Zhu, Radiat. Eff. Defects Solids 130-131 (1994) 211.

[11] H. Yasumatsu, T. Kondow, Rep. Prog. Phys. 66 (2003) 1783.

[12] G.H. Takaoka, H. Noguchi, M. Kawashita, Nucl. Inst. Methods Phys. B242 (2006) 417

[13] G.H. Takaoka, K. Nakayama, H. Noguchi, M. Kawashita, Surf. Interface Anal. 38 (2006) 1534.

[14] Z. Insepov, I. Yamada, Surf. Rev. Lett. 3 (1996) 1023.

[15] G.H. Takaoka, H. Noguchi, K. Nakayama, Y. Hironaka, M. Kawashita, Nucl. Inst. Methods Phys. B237 (2005) 402

[16] S.B. Amor, G. Baud, M. Jacquet, G. Mamse, P. Fioux, M. Nardin, Appl. Surf. Sci. $153(2000) 172$. 


\section{Figure Captions}

Figure 1: Dependence of sputtered depth of $\mathrm{Si}(100)$ and $\mathrm{SiO}_{2}$ surfaces on acceleration voltage for water cluster ions. The fluence was $1.0 \times 10^{16}$ ions $/ \mathrm{cm}^{2}$.

Figure 2: Sputtered depth for PMMA, PET and PC surfaces irradiated at different acceleration voltages by water cluster ion beams. The fluence was $1.0 \times 10^{16}$ ions $/ \mathrm{cm}^{2}$.

Figure 3: C1s peaks for PMMA surfaces (a) unirradaited and irradiated at acceleration voltages of (b) $3 \mathrm{kV}$ and (c) $9 \mathrm{kV}$. The fluence was $1.0 \times 10^{16}$ ions $/ \mathrm{cm}^{2}$.

Figure 4: Micropattern etched onto the PMMA substrate with water cluster ion beams. 


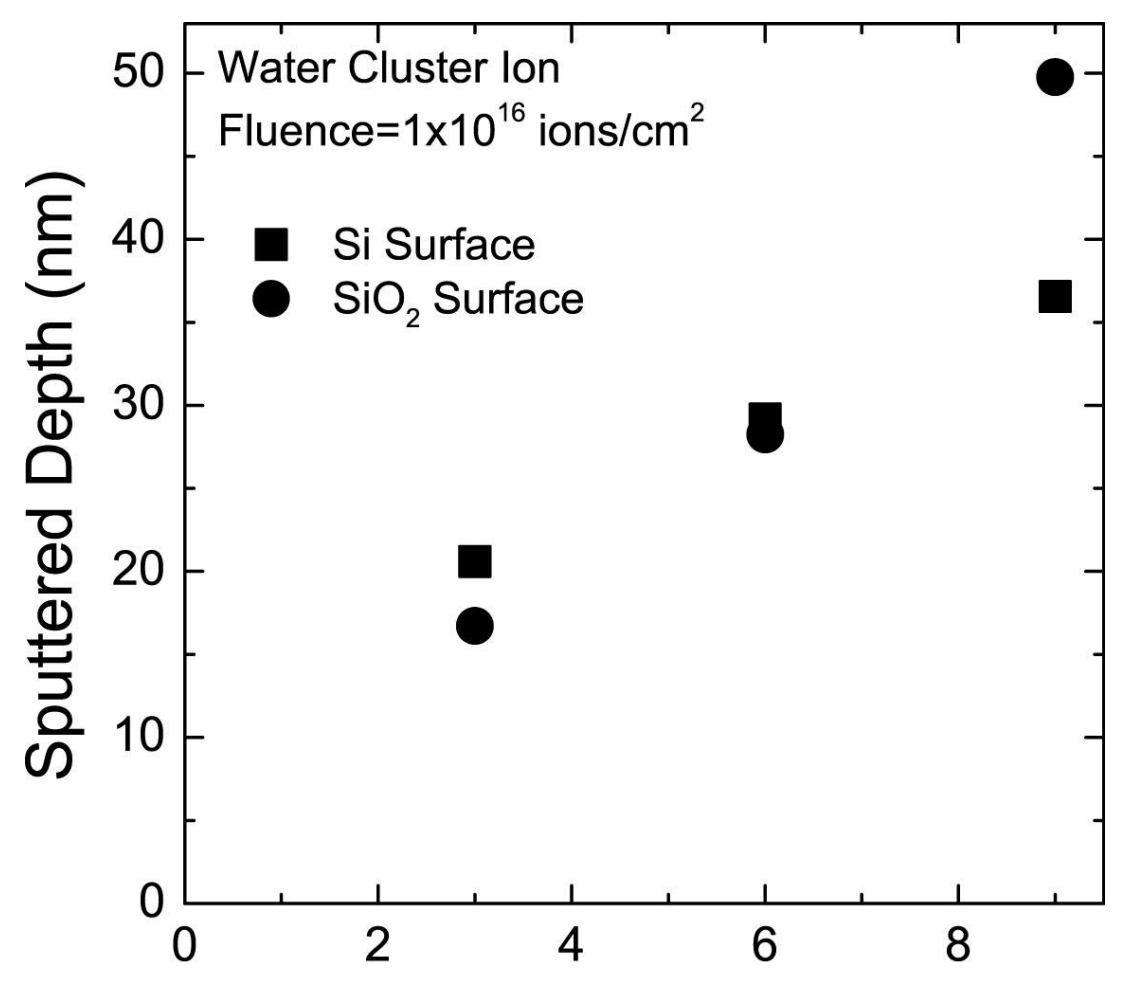

Figure 1: Takaoka et al. 


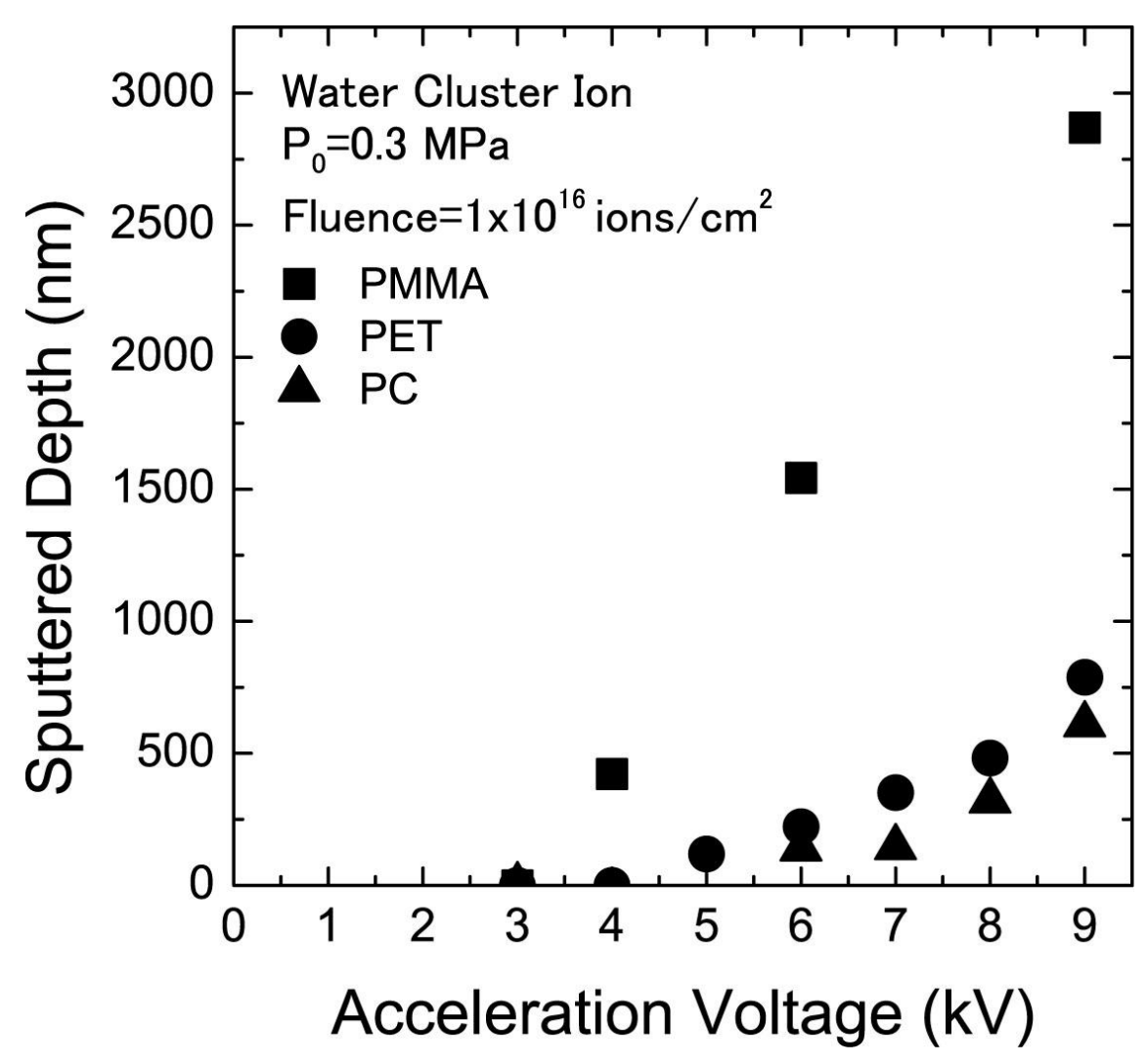

Figure 2: Takaoka et al. 

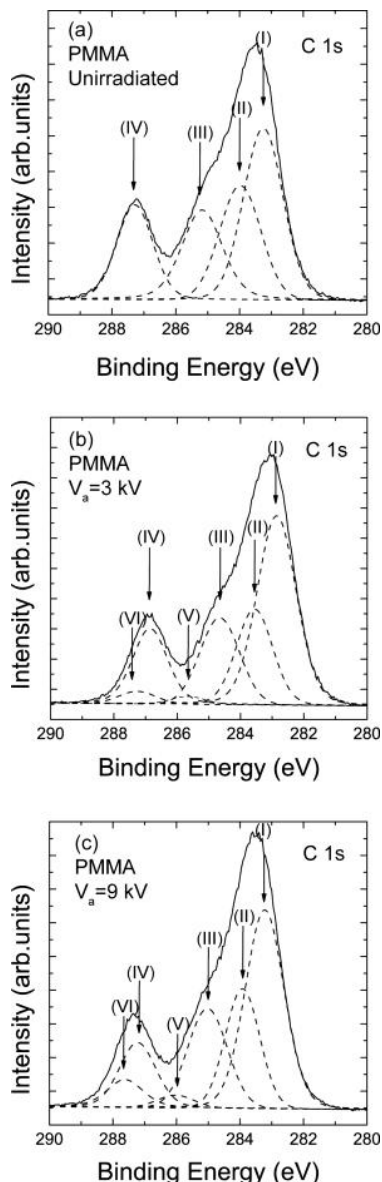

Figure 3: Takaoka et al. 


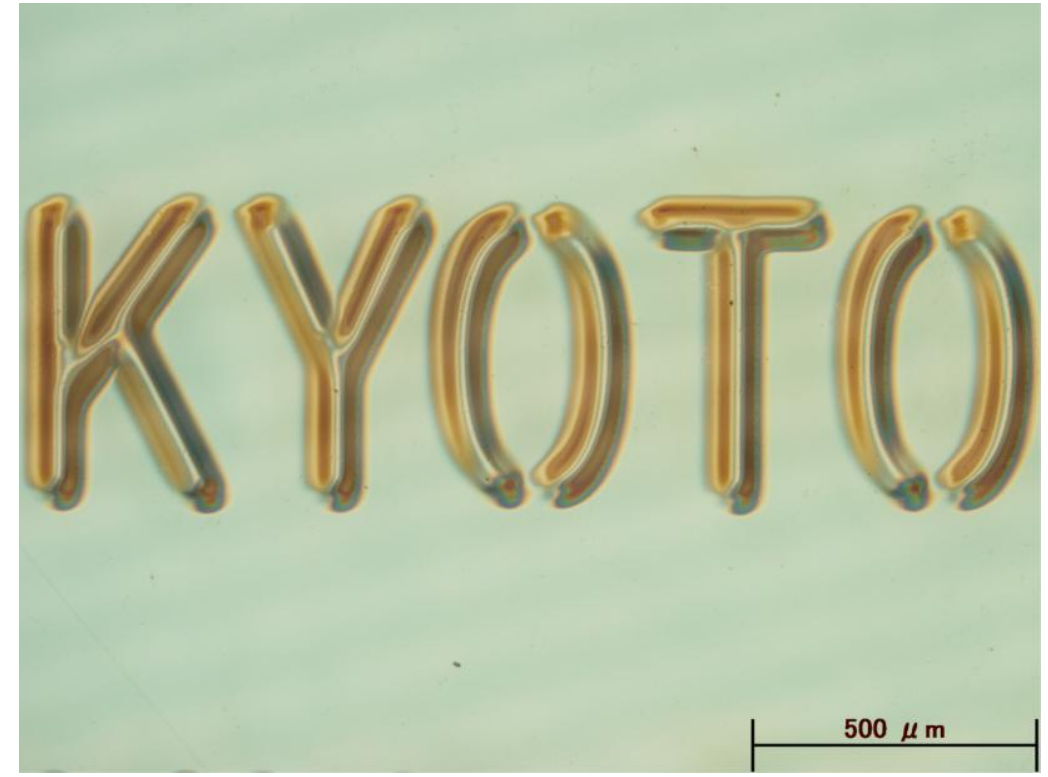

Figure 4: Takaoka et al. 